DOI: https://doi.org/10.47405/mjssh.v5i6.429

\begin{tabular}{|c|c|}
\hline $\cos ^{2}=$ & Malaysian Journal of Social Sciences and Humanities (MJSSH) \\
\hline $\begin{array}{l}\text { Malaysian Journal of } \\
\text { Socali sciences and }\end{array}$ & Volume 5, Issue 6, June 2020 \\
\hline (MJ - SSH) & e-ISSN : 2504-8562 \\
\hline$=$ & $\begin{array}{l}\text { Journal home page: } \\
\text { www.msocialsciences.com }\end{array}$ \\
\hline
\end{tabular}

\title{
Kebolehgunaan Massive Open Online Course (MO0C) Sebagai E-Pembelajaran dalam Pengajaran Pengaturcaraan di Sekolah Menengah
}

\author{
Nur Shafinaz Binti Ahmad Shakir1, Nor Hafizah Binti Adnan' ${ }^{1}$ \\ ${ }_{1}^{1}$ Fakulti Pendidikan, Universiti Kebangsaan Malaysia (UKM)
}

Correspondence: Nur Shafinaz Binti Ahmad Shakir (finazshakir95@gmail.com)

\begin{abstract}
Abstrak
Kementerian Pendidikan Malaysia (KPM) menyarankan agar guru-guru sentiasa berinovasi dalam merancang strategi pengajaran dan pembelajaran (PdP) mengikut perkembangan teknologi terkini. Kaedah pengajaran dan pembelajaran (PdP) amat penting bagi memastikan guru menyampaikan pembelajaran dengan berkualiti dan murid mudah memahami proses pengajaran yang berlaku terutamanya bagi matapelajaran yang melibatkan pengaturcaraan. Hal ini kerana pengaturcaraan merupakan satu pembelajaran yang sangat kompleks dan sukar difahami. Oleh yang demikian, epembelajaran merupakan satu kaedah pedagogi yang diperkenalkan bagi memudahkan pelajar memahami konsep pengaturcaraan dengan berkesan. Tujuan kajian ini dijalankan adalah untuk mengkaji kebolehgunaan e-pembelajaran menggunakan platform Massive Open Online Learning (MOOC) dalam pengajaran pengaturcaraan di sekolah menengah. Kajian ini menggunkan reka bentuk kuasi-eksperimen iaitu melibatkan seramai 60 orang sampel yang terdiri daripada pelajar Tingkatan 3 Sekolah Kebangsaan Seri Muda. Sampel ini dibahagikan kepada dua kumpulan iaitu 30 orang pelajar daripada kumpulan kawalan dan 30 orang pelajar daripada kumpulan rawatan. Kajian mendapati kedua-dua kumpulan kawalan dan rawatan mempunyai pengetahuan sedia ada pada tahap sederhana. Manakala hasil ujian $t$ menunjukan terdapat perbezaan min yang signifikan pencapaian ujian pra dan pasca antara kumpulan kawalan dan kumpulan rawatan. Kajian ini membuktikan bahawa penggunaan e-pembelajaran MOOC dapat meningkatkan tahap pengetahuan pelajar walaupun hasil dapatan t-test menunjukan perbezaan peningkatan ujian pra dan pasca bagi kumpulan rawatan hanya sedikit.
\end{abstract}

Kata kunci: e-pembelajaran, platform pembelajaran digital, pengaturcaraan, Massive Open Online Learning (MOOC)

\section{The Usefulness of Massive Open Online Course (MOOC) as an E-Learning in Secondary Programming Teaching}

\begin{abstract}
The Ministry of Education Malaysia (MOE) recommends that teachers are constantly innovating in designing teaching and learning strategies (PdP) in keeping with the latest technological developments. Teaching and learning (PdP) methods are essential to ensure that teachers deliver quality learning so students are easy to understand the teaching process that is taking place especially for subjects involving programming. This is because programming is a very complex and difficult learning process. Therefore, e-learning is a pedagogical method introduced to facilitate students to understand the concept of programming effectively. The purpose of this study was to investigate the usefulness of elearning using the Massive Open Online Learning (MOOC) platform in teaching programming in
\end{abstract}


secondary school. The study utilized a quasi-experimental design involving 60 sample students from SMK Seri Muda. The sample was divided into two groups of 30 students from the control group and 30 students from the treatment group. The study found that both control and treatment groups had existing knowledge at a moderate level. Whereas $t$ test results showed significant mean difference between preand post-test results between the control and treatment groups. This study demonstrates that the use of MOOC e-learning can improve students' knowledge level even though t-test findings indicate that differences in pre- and post-test tests differ for treatment groups.

Keywords: e-learning, digital learning platform, Massive Open Online Learning (MOOC)

\section{Pengenalan}

Pendidikan yang berkualiti penting dalam melahirkan lebih ramai generasi ilmuan dan pakar dalam pelbagai bidang. Perkembangan pendidikan haruslah seiring dengan perkembangan teknologi dan komunikasi kerana teknologi yang semakin canggih membantu para pendidik untuk menyampaikan pengajaran dengan lebih berkesan dan efektif (Farhana, 2017). Menurut Noraya (2017), Pelan Pembangunan Pendidikan Malaysia menunjukan pendidikan di Malaysia berada pada gelombong ke-2 (2016-2020) iaitu fasa memacu teknologi komunikasi dan maklumat melalui pembelajaran jarak jauh dan pembelajaran secara kendiri. Justeru itu, pembelajaran jarak jauh dan pembelajaran secara kendiri boleh dilakukan dengan hanya menggunkan platform-platform e-pembelajaran. Penggunaan teknologi perlu dipraktikan dalam pendidikan kepada generasi baru agar mereka tidak buta IT dan tidak hanya menganggap teknologi hanya semata-mata untuk tujuan komunikasi tetapi sebenarnya teknologi juga diperlukan dalam pendidikan.

Menurut Begona (2016), konsep e-pembelajaran dapat didefinisikan sebagai satu kaedah menyampaikan sesuatu pengajaran dalam talian dan kaedah ini dapat memudahkan pendidik dan pelajar menjalankan kelas melalui alam maya. E-Pembelajaran juga membolehkan pelajar memahami pengajaran yang dijalankan kerana kaedah yang digunapakai bersifat interaktif dan dapat menarik minat pelajar untuk belajar. Vidya (2016) juga menyatakan bahawa e-pembelajaran merupakan satu proses pengajaran yang sistematik dengan menggunakan sistem elektronik atau komputer. Pelajar boleh mengulangkaji pelajaran berulangkali dan bertanyakan kepada pendidik atau rakan melalui medium yang disediakan dalam platform e-pembelajaran. Justeru, penggunakan e-pembelajaran dilihat sangat membantu pendidik dan pelajar menjalankan proses pengajaran dan pembelajaran. Terdapat pelbagai platform e-pembelajaran sama ada boleh diakses secara percuma dan berbayar. Setiap platform mempunyai kelebihan tersendiri dan boleh digunakan bagi tujuan pembelajaran. Antara platform-platform yang boleh diakses secara percuma seperti Massive Open Online Courses (MOOC), Moodle, Blog, Olat dan sebagainya. Pendidik perlu bijak menggunakan kaedah pedagogi terkini dalam menyampaikan pengajaran mengikut peredaran masa. Hal ini ditegaskan oleh Mohd Azizol (2011) bahawa pendidik perlu merubah cara pengajaran dan pembelajaran yang lebih kreatif dan beliau menyifatkan e-pembelajaran sebagai "Pedagogy empowered by digital technology".

Dunia menghadapi Revolusi Industri ke-4, pendidikan Pengaturcaraan merupakan salah satu bidang yang amat penting diceburi oleh pelajar (Marini, 2018). Menurut Murai (2016) dan Nelson (2016), negara maju seperti Amerika Syarikat dan Jepun telah memperkenalkan pengaturcaraan kepada pelajar sekolah rendah. Pengaturcaraan komputer merupakan salah satu kemahiran yang memerlukan pelajar menggunakan kemahiran berfikir secara kritis untuk menguasai pembelajaran tersebut. Kementerian Pendidikan Malaysia (KPM) telah memperkenalkan matapelajaran Asas Sains Komputer (ASK) pada peringkat sekolah pada tahun 2017. Tujuan ASK dirancang adalah untuk memperkenalkan pengaturcaraan dan pelajar mahir dalam bidang teknologi serta dapat menyelesaikan masalah menggunakan kemahiran berfikir aras tinggi (Talib, 2016). Oleh itu, pengetahuan pendidikan pengaturcaraan merupakan satu peluang yang harus pelajar terokai.

Pembelajaran Pengaturcaraan Scratch atau Asas Sains Komputer (ASK) dilihat sangat kompleks dan memerlukan kaedah pengajaran dan pembelajaran yang berkesan. Kaedah pembelajaran secara 
tradisional atau konvensional kurang meningkatkan kefahahaman pelajar kerana kebiasaanya guru hanya menyampaian maklumat secara satu hala dan menyampaikan kandungan dengan hanya menggunakan nota dan buku teks tanpa mengira tahap penerimaan dan pemahaman pelajar (Noraini \& Norazilawati, 2017). Oleh itu, kaedah e-pembelajaran merupakan satu platform yang dapat membantu para guru melakukan satu perubahan dalam menyampaikan pembelajaran dengan lebih baik (Harandi, 2015).

Laporan Forum Ekonomi Dunia iaitu The Future of Jobs: Employment, Skill and Workforce Strategy for the Fourth Industrial Revolution yang dikeluarkan pada Januari 2016 mendedahkan keupayaan kognitif menjadi antara ciri penting yang perlu dimiliki oleh tenaga kerja akan datang. Perlaksanaan standard pembelajaran baru telah dilakukan pada tahun 2017 iaitu Kementerian Pelajaran Malaysia (KPM) telah menggantikan standard melaksanakan Kurikulum Bersepadu Sekolah Menengah (KBSM) dan Kurikulum Bersepadu Sekolah Rendah (KBSR) kepada Kurikulum Standard Sekolah Menengah (KSSM) dan Kurikulum Standard Sekolah Rendah (KSSR) supaya pendidikan di Malaysia berada dalam lingkungan pendidikan yang terbaik di peringkat antarabangsa.

Melalui KSSM, satu matapelajaran pilihan telah ditawarkan iaitu Sains Komputer untuk pelajar Tingkatan 4 dan Tingkatan 5. KSSM Sains Komputer direkabentuk untuk melahirkan pelajar yang mempunyai kemahiran pemikiran komputasional dan kemahiran kritikal melalui keupayaan merekabentuk, membangunkan serta mencipta aplikasi dan sistem. Beberapa negara telah memperkenalkan pengaturcaraan kepada kanak-kanak seawal usia 5 tahun. Namun di Malaysia, bilangan pelajar yang meminati bidang Sains Komputer kurang. Pelajar dimogokan tentang isu susah untuk mempelajari Sains Komputer. Mereka tidak berminat dengan pengaturcaraan.

Di peringkat universiti, pendidik yang terlibat dengan subjek pengaturcaraan terutama untuk pelajar tahun pertama sering menghadapi cabaran dalam membentuk kefahaman pelajar berkaitan konsep pengaturcaraan dan seterusnya memberi kesan terhadap kemahiran pelajar menyelesaikan masalah yang diberikan (Yusof, 2017). Menurut Falkner dan Palmer (2009), Soloway dan Sphohrer (2013) kemahiran pengaturcaraan memberi banyak cabaran kepada individu yang baru mula menceburi ilmu pengaturcaraan.

Masalah ini merupakan masalah universal. Pembelajaran untuk memahami dan kod program komputer secara meluas dianggap sangat mencabar dalam pendidikan sains komputer kerana permintaan untuk tahap keupayaan praktikal dan bukan teori sahaja. Pendidikan dalam bilik darjah tidak cukup untuk menghasilkan pengaturcaraan yang baik. Individu selalu meminta bantuan daripada seseorang yang mempunyai lebih banyak pengalaman atau sumber lain, seperti buku atau Internet. Keadaan ini menyebabkan motivasi pelajar rendah dan pelajar berhenti dari mempelajari kursus Sains Komputer (Hoc, 1990; Robins, Rountree \& Rountree, 2003).

Disamping itu, guru sebagai agen pendidik juga menghadapi cabaran besar dalam mendidik pelajar dalam matapelajaran melibatkan pengaturcaraan. Hal ini juga ditegaskan oleh (Alammary A, 2019) bahawa mengajar pengaturcaraan bukan sesuatu tugasan yang mudah. Pendidik juga perlu berhadapan dengan kaedah pedagogi yang sesuai mengikut ciri-ciri seorang pelajar. Setiap pelajar mempunyai tahap kognitif yang berbeza-beza. Oleh itu, kaedah pengajaran dan pembelajaran yang sesuai perlu dititikberatkan oleh guru terutamanya bagi mata pelajaran yang melibatkan pengaturcaraan.

Tujuan kajian ini dijalankan bagi mengkaji kebolehgunaan e-pembelajaran MOOC dalam pembelajaran Pengaturcaraan Scratch bagi pelajar-pelajar sekolah menengah. Hipotesis kajian ini melihat adakah terdapat perbezaan min yang signifikan antara kumpulan rawatan yang diberi intervensi iaitu pembelajaran menggunakan MOOC dengan kumpulan kawalan yang menggunakan kaedah konvensional.

Negara mengalami satu lonjakan baru dalam mengapai Wawasan 2020. Melalui Wawasan 2020, Malaysia berhasrat untuk melahirkan masyarakat yang pakar dalam bidang teknologi. Hal ini kerana, di Amerika Syarikat, 60\% bidang pekerjaan melibatkan teknologi. Menurut Grandl et. al (2018), pengaturcaraan adalah kemahiran tambahan yang penting pada abad ke 21. Pengaturcaraan merupakan 
satu proses membangunkan atur cara melalui kod arahan dalam menyelesaikan sesuatu masalah. Proses pengaturcaraan memerlukan kemahiran berfikir secara komputasional dan logik serta pengetahuan yang luas (Yildiz, 2018; Yildiz \& Guyer, 2019; Yildiz \& Karaoglan, 2019). Hal ini dapat membantu pelajar membina kemahiran berkomunikasi, kreatif, kemahiran berkolaborasi, kemahiran menyelesaikan masalah dan kemahiran kendiri (Lau \& Yuen, 2011).

Dasar negara di Eropah menekankan keperluan untuk melahirkan warga negara yang kompetensi dalam menggunakan digital teknologi secara kritikal dan kreatif (Papadakis, 2016; Redecker, 2017). Menurut Balanskat (2014) dan Mannila (2014), beberapa negara telah memperkenalkan Pengaturcaraan atau Sains Komputer bukan hanya kepada pelajar sekolah rendah malah kanak-kanak juga mempelajari pengaturcaraan. Berbeza di Malaysia, pelajar baru didedahkan kepada mata pelajaran Teknologi Maklumat dan Komunikasi (TMK) bagi sekolah rendah, Asas Sains Komputer (ASK) bagi pelajar Tingkatan 1, 2 dan 3 manakala Tingkatan 4 dan Tingkatan 5, KPM memperkenalkan mata pelajaran Sains Komputer. Namun tidak semua sekolah di Malaysia yang menawarkan bidang Sains Komputer di sekolah dan bilangan yang mendaftar subjek tersebut masih sedikit.

Scratch adalah satu aplikasi yang telah dibina bagi memudahkan pelajar mempelajari pengaturcaraan dengan lebih mudah. Scratch menggunakan pendekatan animasi agar pelajar dapat mengkodkan program dengan jelas (Ismail et. al, 2016). Menurut Jennifer (2017), Pengaturcaraan Scratch adalah satu bahasa pengaturaraan yang interaktif yang dibina untuk membantu pelajar belajar matematik dan membina kemahiran berfikir secara komputasional. Scratch mula dibina oleh sebuah organisasi iaitu sekumpulan penyelidik iaitu The Massachusetts Institute of Technology (MIT) Media Lab's Lifelong Kindergarten Group.

Scratch juga dibina untuk menyokong kanak-kanak dan novis untuk melalui proses pembelajaran secara eksperimen dan mengasah kemahiran berfikir secara kreatif dengan melontarkan idea melalui pengkodan. Menurut Wing (2006) dan Yadav (2014), Pemikiran komputasional penting dan ia merupakan kemahiran asas yang diperlukan oleh setiap orang. Pemikiran komputasional bermaksud satu proses menyelesaikan sesuatu masalah dengan kreatif dan kritikal. Pemikiran ini amat penting dipupuk dalam diri pelajar. Pemikiran komputasional bukan sahaja digunakan dalam pengaturcaraan malah matapelajaran lain seperti Matematik, Fizik, Kimia dan sebagainya diperlukan. Antara salah satu langkah dalam membina kemahiran tersebut adalah dengan menawarkan matapelajaran yang melibatkan pengaturcaraan. Melalui pengkodan, pelajar perlu berfikir secara kreatif dan kritis bagi menyelesaikan sesuatu tugasan. Menurut Gagne (1985), pengaturcaraan merupakan satu pembelajaran yang penting dalam membina kemahiran menyelesaikan masalah kerana ia melibatkan proses try and error di mana pelajar dapat mengenalpasti sebab dan akibat sesuatu proses pengkodan dihasilkan. Pengaturcaraan Scratch digunakan oleh ramai pelajar sekola rendah dan ahli-ahli kelab pengkodan di seluruh negara kerana Scratch hanya melibatkan proses "drag and drop". Namun begitu, pembelajaran secara tradisional iaitu bersemuka tidak cukup untuk pelajar memahami konsep asas sains komputer dan membina pengetahuan yang kompleks.

Hal ini dipersutujui oleh Ouhbi (2015) yang menyatakan proses pengajaran pengaturcaraan kurang berkesan disebabkan oleh teknik pengajaran yang lemah, kurang interaksi pelajar dan pelajar tidak berminat dalam pengaturcaraan. Ouhbi mencadangkan mengunakan teknik pedagogi menggunakan digital untuk menarik minat pelajar dalam pengaturcaraan. Ali (2016) juga menyatakan bahawa pengaturcaraan merupakan satu tugasan yang mencabar dan hanya dapat dilakukan oleh individu yang mempunyai tahap latihan yang tinggi. Oleh itu, pendekatan pedagogi guru yang sesuai dan berkesan perlu diambil kira bagi membolehkan pelajar memperoleh pengetahuan dengan lebih baik.

Menurut Mc Donald (2006), pembelajaran secara "blended learning" mula diguna pakai oleh korporat dalam bidang perniagaan. Namun "blended learning" telah berkembang dalam bidang pendidikan bagi mengantikan pembelajaran secara tradisional. Konsep asas pembelajaran "blended learning" ialah kaedah pembelajaran secara tradisional iaitu pembelajaran secara bersemuka dengan gabungan pembelajaran secara digital menggunakan teknologi seperti cd, internet, video dan sebagainya. Antara kelebihan "Blended Learning" ialah pelajar dan pendidik lebih fleksibel menggunakan masa dalam mempelajari pengaturcaraan. Mereka boleh mempelajari sesuatu pelajaran pada bila-bila masa dan di 
mana sahaja. Selain itu, pembelajaran secara "blended learning" membolehkan mereka mendapatkan nota-nota melalui platform pembelajaran seperti MOOC, Moodle dan sebagainya. Pembelajaran dapat dilakukan secara kumpulan mahupun individu.

Kebanyakan online coding tidak membolehkan pelajar mendapat maklum balas, jika ada pun maklum balas, pelajar tidak dapat menguasai ilmu atau mempraktikan komen yang telah diberi (Ada 2015). Platform Massive Open Online Course (MOOC) ialah satu pendekatan e-pembelajaran yang kini digunakan oleh pelbagai institusi di peringkat tinggi. MOOC merupakan platform atas talian yang boleh digunakan secara percuma dan boleh diakses oleh pelajar lain (Friss, 2016). Menurut Friss (2016) lagi, MOOC telah digunapakai oleh tenaga pengajar profesional untuk mengajar pengaturcaraan dan sains komputer kepada pelajar di peringkat tinggi manakala masih kurang diperkenalkan kepada pelajar di peringkat sekolah. Di Malaysia, Kementerian Pendidikan Malaysia (KPM) telah merangka perubahan baru dalam sistem pendidikan selari dengan perkembangan teknologi semasa. Namun, tahap penerimaan dan penggunaannya oleh guru masih lagi menjadi persoalan utama. Berdasarkan kajiankajian lepas, pengintegrasian teknologi web (ICT) dalam proses pembelajaran pelajar, diyakini mampu membawa kesan positif kepada pencapaian pelajar (Abdulahi, NorHidayati \& Elmi, 2012; Pettiward, 2011; Songkram, 2015).

Kepelbagaian kaedah dan penggunaan teknologi dalam melaksana aktiviti pembelajaran mampu menggalakkan penyertaan aktif para pelajar dan dijangka mampu meningkatkan keberhasilan pencapaian matlamat pembelajaran pelajar (Mohd Azli \& Abdul Latif, 2012). Manakala Mohd Azli, Wong \& Goh, 2016; Mohd Azli, Wong \& Noraini, 2016) menyatakan bahawa proses pembelajaran menggunakan pendekatan pembelajaran teradun merupakan satu pendekatan yang berupaya untuk menangani keperluan kepelbagaian gaya pembelajaran pelajar dalam menghasilkan impak positif kepada kemahiran pelajar.

Secara kesimpulan, matapelajaran Asas Sains Komputer bagi menengah rendah dan Sains Komputer bagi menengah atas merupakan satu inisiatif baik pihak KPM dalam melahirkan rakyat kompeten terhadap teknologi maklumat dan teknologi digital. Teknik pengajaran dan pengajaran yang efektif mampu menarik lebih ramai minat pelajar dan meningkatkan pengetahuan pelajar. Pengajaran dan pembelajaran secara teradun dengan menggunakan platform MOOC dapat memberi impak positif kepada pelajar. Kajian ini dilakukan untuk melihat kebolehgunaan MOOC sebagai platform pengajaran dan pembelajaran pengaturcaraan di peringkat sekolah dapat dilaksanakan.

Menurut Chiu (2015), Teori Kognitif Pembelajaran Multimedia boleh didefinisi sebagai satu konsep pembelajaran menggunakan visual dan audio. Pelajar hanya boleh memproses maklumat secara terhad dalam sesuatu selang masa (Mayer, 2009). Hal ini kerana menurut Baddelley (1992), apabila pelajar diberi maklumat yang banyak pada satu masa, mereka mungkin tidak dapat memproses maklumat. Pemprosesan kognitif yang berlebihan ini dipanggil beban kognitif, yang boleh menyebabkan pelajar cepat hilang tumpuan semasa pembelajaran dijalankan. Pengajaran dan pembelajaran akan lebih efektif jika bahan pengajaran atau kaedah pengajaran itu menggunkan gabungan elemen tulisan, gambar, audio dan video (Mayer, 2011). Menurut Mesyun (2016), pelajar mempunyai dua saluran untuk memproses maklumat iaitu menerusi pembahagian kerja melalui visual dan lisan. Maklumat yang diperolehi melalui audio akan dipindahkan ke saluran lisan manakala maklumat berbentuk teks dan grafik akan diproses melalui saluran visual. Dengan menggunakan teori pembelajaran multimedia ini, maklumat yang diperoleh dari pelajar dapat diproses dan disimpan dengan lebih lama oleh memori jangka masa panjang (long term memory).

E-pembelajaran MOOC merupakan salah satu kaedah pengajaran dan pembelajaran yang menggunakan teori kognitif pembelajaran multimedia Mayer. E-pembelajaran menggunakan elemenelemen multimedia seperti video, laman web interaktif, penggunaan teks dan audio. Modul epembelajaran yang dibangunkan haruslah disusun dan mengikut aras kognitif pelajar mengikut kesesuaian agar pendidik dapat menarik minat pelajar dalam pembelajaran (Afiqah, 2017). Hai ini diperkukuh dengan kenyataan Syamsulaini (2016) yang menjelaskan bahawa penggunaan media di dalam proses pendidikan akan menambah proses pemahaman pelajar lebih mendalam dan menjadikan aktiviti pembelajaran yang lebih pelbagai. Oleh demikian, pendidik boleh menggunakan pendekatan 
pengajaran melalui MOOC dengan menghasilkan kandungan modul yang lebih interaktif dengan memasukkan beberapa elemen multimedia supaya pelajar lebih mudah memahami pengajaran.

Selain itu, pelajar juga tidak boleh hanya bergantung kepada pengetahuan yang disampaikan oleh pendidik semata-mata. Pelajar perlu aktif membina pengetahuan dalam minda mereka sendiri. Menurut Bereiter (1994), teori pembelajaran konstruktivisme adalah berdasarkan pemerhatian dan kajian saintifik. Seseorang itu dapat membina pemahaman dan pengetahuan melalui pengalaman-pengalaman yang mereka lalui. Pengetahuan dapat dijana apabila seseorang sentiasa bertanya soalan dan bersungguh-sungguh ingin meneroka sesuatu ilmu.

Guru akan membimbing pelajar dalam menjalankan eksperimen dan melakukan penyelesaian masalah dunia sebenar. Guru akan memastikan pelajar memahami konsep-konsep asas sesuatu pembelajaran. Antara ciri-ciri teori pembelajaran kostruktivisme ialah pengetahuan yang diperoleh akan dikongsi oleh guru atau pelajar. Selain itu, guru adalah sebagai pembimbing yang akan memberi tunjuk ajar kepada pelajar. Pembelajaran secara kumpulan kecil juga merupakan salah satu pendekatan pembelajaran berasaskan teori konstruktivisme.

Antara kelebihan pendekatan pembelajaran berasaskan teori konstruktivisme ialah pelajar akan lebih aktif dalam kelas dan mereka dapat belajar berfikir dan memahami konsep dengan baik berbanding hanya mengingat sesuatu konsep pembelajaran dan apabila habis peperiksaan mereka akan lupa apa yang mereka belajar. Menurut Bada (2015), pembelajaran konstruktivisme dapat meningkatkan kemahiran berkomunikasi kerana di dalam kelas, mereka banyak melakukan aktiviti-aktiviti perbincangan dan berkongsi pendapat. Pendekatan pembelajaran konstruktivisme merangsang diri mereka untuk meneroka dan bertanya sesuatu yang tidak diketahui.

Kedua-dua teori pembelajaran ini (teori kognitif pembelajaran multimedia dan teori pembelajaran konstruktif) merupakan kaedah yang dapat membantu pelajar menghubungkait pengetahuan baru dengan pengetahuaian sedia ada. Pelajar akan lebih memahami konsep berbanding hanya menghafal konsep. Kaedah-kaedah ini boleh melatih pelajar menyelesaikan masalah secara kritis dan ia merupakan pendekatan yang sesuai dalam pengajaran dan pembelajaran zaman sekarang terutamanya terhadap matapelajaran yang melibatkan pengaturcaraan.

\section{Metod Kajian}

Kajian ini adalah bagi mengenalpasti dan mengkaji secara empirikal dan sistematik berkaitan pengunaan MOOC sebagai platform e-pembelajaran dalam pengaturcaraan Scratch bagi pelajar sekolah menengah. Kajian ini menggunakan reka bentuk kajian kuasi eksperimen. Kajian ini melibatkan dua kumpulan iaitu kumpulan kawalan dan kumpulan rawatan. Kumpulan rawatan diberi intervensi iaitu penggunaan MOOC dalam mempelajari pengaturcaraan Scratch manakala kumpulan kawalan menggunakan kaedah tradisional atau konvensional dalam mempelajari pengaturcaraan Scratch. Kedua-dua kumpulan perlu menjawab soalan ujian pra sebelum pengajaran dimulakan dan ujian pasca selepas pengajaran dan intervensi dilakukan.

Populasi yang dijalankan dalam kajian ini terdiri daripada pelajar Sekolah Menengah Kebangsaan Sri Muda Penaga. Sampel ini diambil dari kalangan pelajar Tingkatan 3 dari dua buah kelas. Sampel terdiri daripada 30 orang pelajar kumpulan kawalan dan 30 orang pelajar kumpulan rawatan. Sampel yang telah dipilih telah diatur oleh pihak sekolah.

Instrumen kajian yang digunakan adalah soalan ujian. Set soalan ujian Pengaturcaraan Scratch digunakan untuk melihat tahap kefahaman pelajar sebelum dan selepas kajian dilakukan. Soalan ujian dibina mengandungi 2 bahagian iaitu bahagian A dan B. Soalan ujian pra dan pasca berbentuk serupa cuma dijalankan pada waktu berbeza. Ujian Pra akan dijalankan sebelum memulakan pengajaran bagi melihat pengetahuan awal pelajar manakala ujian Pasca dilakukan sebelah pengajaran dan intervensi dilakukan. 
Bahagian A mempunyai item soalan sebanyak 8 soalan. Soalan bahagian A berbentuk objektif manakala bahagian B mempunyai 2 soalan berbentuk subjektif. Para pelajar harus menjawab 10 soalan dalam masa 20 minit. Soalan-soalan Ujian Pra dan Pasca terdiri daripada subtopik yang telah dipilih iaitu Pengenalan Pengaturcaraan, Algorithma, Pseudokod dan Carta Alir dan Penghasilan dan Pengujian Atur Cara.

\section{Dapatan Kajian}

Dapatan kajian ini dihuraikan berdasarkan objektif yang telah ditetapkan dalam kajian ini. Objektif utama kajian ini adalah untuk mengetahui tahap kebolehgunaan kaedah e-pembelajaran MOOC dalam pengajaran dan pembelajaran pengaturcaraan Scratch bagi pelajar Tingkatan 3 Sekolah Kebangsaan Seri Muda. Ujian T berpasangan (Paired Sample T-Test) digunakan untuk menganalisis data statistik inferensi manakala min dan sisihan piawai digunakan dalam menganalisis data statistik deskriptif.

\section{Analisa pengetahuan awal yang sedia ada bagi pelajar kumpulan kawalan dan rawatan terhadap pengaturcaraan Scratch}

Jadual 1 menunjukan tahap pengetahuan awal yang sedia ada dalam kalangan pelajar Tingkatan 3 terhadap subtajuk pengaturcaraan Scratch. Berdasarkan jadual tersebut, purata skor tahap pengetahuan awal bagi kumpulan rawatan ialah $\mathrm{M}=14.10$ manakala bagi kumpulan kawalan pula $\mathrm{M}=14.20$. Berdasarkan keputusan analisis, hanya terdapat perbezaan yang sedikit tahap pengetahuan awal pelajar Tingkatan 3 dalam kumpulan kawalan dan kumpulan rawatan. Tahap pengetahuan awal sedia ada pelajar bagi kedua-dua kumpulan berada pada tahap yang sederhana.

Jadual 1: Skor tahap pengetahuan sedia ada pelajar kumpulan rawatan dan kumpulan kawalan

\begin{tabular}{lccccc} 
& N & Minumum & Maximum & Min & $\begin{array}{c}\text { Sisihan } \\
\text { Piawaian }\end{array}$ \\
\hline $\begin{array}{l}\text { Ujian Pra } \\
\text { Kumpulan } \\
\text { Rawatan }\end{array}$ & 30 & 8 & 18 & 14.10 & 2.869 \\
$\begin{array}{l}\text { Ujian Pra } \\
\text { Kumpulan }\end{array}$ & 30 & 10 & 19 & 14.20 & 2.26518 \\
$\begin{array}{l}\text { Kawalan } \\
\text { Valid N (listwise }\end{array}$ & 60 & & & & \\
\hline
\end{tabular}

\section{Analisa Perbezaan Signifikan Antara Skor Min Ujian Pra dan Ujian Pasca Kumpulan Rawatan}

Ujian T-berpasangan digunakan untuk menganalisis data bagi melihat perbezaan signifikan antara skor min ujian pra dan ujian pasca bagi kumpulan rawatan. Bagi kumpulan rawatan satu intervensi dilakukan iaitu kaedah pembelajaran e-learning menggunakan platform Massive Open Online Course (MOOC) dilakukan.

Jadual 2: Ujian T Berpasangan bagi melihat perbezaan signifikan skor min ujian pra dan ujian pasca kumpulan rawatan

\begin{tabular}{cccccccc}
\hline Kumpulan & Ujian & Bil & $\begin{array}{c}\text { Skor } \\
\text { Min. }\end{array}$ & $\begin{array}{c}\text { Perbezaan } \\
\text { Min }\end{array}$ & $\begin{array}{c}\text { Sisihan } \\
\text { Piawaian }\end{array}$ & Nilai t & $\begin{array}{c}\text { Tahap } \\
\text { Signifikan }\end{array}$ \\
\hline Rawatan & Pra & 30 & 14.10 & & & & \\
& & & & 2.0 & 3.140 & -3.488 & 0.002 \\
\hline
\end{tabular}




Pasca $\quad 30 \quad 16.10$

Berdasarkan jadual 2 menunjukan nilai t $(30)=-3.488$ dan tahap signifikan, p ialah 0.002 . Tahap signifikan $\mathrm{p}=0.002$ adalah lebih rendah daripada $0.05(\mathrm{p}<0.05)$. Ini menunjukan hipotesis null berjaya ditolak. Jadi dapatan ini menunjukan terdapat perbezaan signifikan skor min ujian pra dan ujian pasca bagi kumpulan rawatan. Intervensi penggunaan Modul MOOC yang dilakukan berjaya walaupun perubahan skor hanya sedikit.

\section{Perbincangan}

Hasil data yang dianalisis menggunakan analisis inferensi dan analisis deskriptif. Ujian $\mathrm{T}$ telah digunakan untuk menganalisis data statistik inferensi. Pertamanya, analisis statistik deskriptif dilakukan bagi melihat pengetahuan awal yang sedia ada bagi pelajar kumpulan kawalan dan rawatan terhadap pengaturcaraan Scratch. Keputusan mendapati tahap pengetahuan awal sedia ada pelajar bagi kedua-dua kumpulan berada pada tahap yang sederhana. Hasil dapatan menunjukan pada peringkat permulaan, kedua-dua kumpulan mempunyai tahap pengetahuan pengaturcaraan Scratch yang sama iaitu pada tahap sederhana.

Kemudian, analisis inferensi ujian $\mathrm{T}$ berpasangan (Paired Sample T-Test) digunakan untuk melihat perbezaan signifikan min ujian pasca kumpulan kawalan dan rawatan. Hasil keputusan menunjukan hipotesis ditolak. Ini bermakna terdapat perbezaan yang signifikan ke atas min skor ujian pasca diantara kumpulan kawalan dan rawatan. Walaupun kedua-dua kumpulan menunjukan peningkatan skor min, namun skor min kumpulan rawtan lebih tinggi berbanding skor min kumpulan kawalan. Secara rumusnya dapat disimpulkan bahawa kaedah pengajaran e-pembelajaran MOOC dilihat membawa kesan positif walaupun peningkatan yang berlaku hanya sedikit. Namun kajian ini berjaya menunjukan bahawa MOOC merupakan satu platform yang boleh meningkatkan kefahaman pelajar dalam pengaturcaraan Scratch. Keputusan yang diperoleh menyokong penyataan Najeh (2019) bahawa kaedah pengintegrasian blended learning dan e-pembelajaran memberi kesan positif terhadap pencapaian pelajar. Beliau juga menyatakan bahawa pendidikan akan lebih berkesan jika pembelajaran bersemuka "face to face" dan penggunaan e-pembelajaran seperti MOOC diaplikasikan dalam pengajaran.

\section{Kesimpulan}

Secara kesimpulannya, dapatan ini menunjukan penggunaan e-pembelajaran MOOC boleh digunakan sebagai satu kaedah pedagogi untuk meningkatkan pengetahuan pelajar. Namun KPM perlu memberi pendedahan kepada guru tentang penggunaan e-pembelajaran kerana masih ramai guru yang tidak menyedari akan kepentingan e-pembelajaran dalam pendidikan. Latihan kaedah penggunaan dan pembinaan modul melalui MOOC perlu diberikan kepada guru-guru agar pengajaran melalui MOOC dapat dilaksankan dengan berkesan. Penyelidik mencadangkan agar tempoh masa kajian harus di pertingkat agar pengkaji dapat melihat keberkesanan modul e-pembelajaran terhadap pencapaian berada pada tahap yang lebih tinggi. Sub topik pembelajaran juga boleh dirancang dengan lebih baik jika masa yang diperuntukan untuk melakukan kajian ini dipertingkatkan.

\section{Rujukan}

Alammary A. (2019). Blended Learning Model for Introductory Programming Courses: A Systematic Literature Review. PLoS ONE. 14(19): e221765.

Bada (2015). Constructivism Learning Theory: A Paradigm for Teaching and Learning. IOSR Journal of Research \& Method in Education (IOSR-JRME), 6(1):66-70.

Begona, G. (2016). Future Trends in the Design Strategies and Technological Affordance of ELearning. Springer International Publishing 2016. 
Farhana Nor Shuhada \& Khalid, F., (2017). Penggunaan Aplikasi Edmodo dalam Program Pengajaran dan Pembelajaran. Pembelajaran Abad ke-21: Trend Integrasi Teknologi hlm 50-57. Bangi: Kuala Lumpur.

Gabriela (2015). A Study about Using E-learning Platform (Moodle) in University Teaching Process. Social and Behviorisme, 180:426-432.

Ibrahim Ouhbi (2015). Learning Basic Programming Concepts by Creating Games with Scratch Programming Environment. Social and Behviorisme. 191:1479-1482.

Ismail, A., Hayati, M., Yatim, M., Sahabudin, N.A., Zuhaidah, N. \& Zain, M. (2016). Keupayaan Murid Sekolah Rendah Mempelajari dan Menerokai Bahasa Pengaturcaraan Visual Capability of Primary School Pupils in Learning and Exploring Visual Programing Language. Journal of ICT in Education. 3: 2289-7844.

Joelle, E. (2017). Improving Student Learning in an Introductory Programming Course using Flipped Classroom and Competency Framework. Global Engineering Education Conferences. 49-55.

Marini Abu Bakar (2018). Kerangka Bagi Persekitaran Pembelajaran Berpusatkan Pelajar Untuk Latihan Pengaturcaraan Kendiri. Asean Journal of Teaching and Learning in Higher Education. 10(1): 24-38.

Mayer, R. E. (2009). Elements of a Science of E-learning. Journal of Educational Computing, 29(3):297-313.

Meysun Hamdi \& Thair Hamtini (2016). Designing an Effectives E-Content Development Framework for the Enchancement of Learning Programming. International Journal of Emerging Technology in Learning (IJET). 1:131-141.

Miftahul Daud (2017). Improving Junior High Schools' Critical Thinking Skills Based on Test Three Different Models of Learning. International Journal of Instruction. 10(1):101-116.

Najeh Rajeh Alsalhi, Mohd Elmagzoub Eltahir \& Sami Sulieman Al-Qatawneh (2019). The Effect of Blended Learning on the Achievement of Ninth Grade Students in Sciences and Their Attitudes Towards its Use. Heliyon 2019.

Nelson, M. (2016). Computer Science Education in the Age of CS for All | HuffPost.

Noraffandy Yahya (2011). Kesediaan Penggunaan E-Learning di Kalangan Pelajar Tahun Dua Kursus Sarjana Muda Sains, Komputer serta Pendidikan di Malaysia. Jurnal of Education Social Science. 1:121-124.

Noraya Elya Mohammad (2017). Penggunaan FROG VLE Sebagai Sistem Pengurusan Pembelajaran (LMS) di Sekolah Seluruh Malaysia. Pembelajaran Abad ke-21: Trend Integrasi Teknologi hlm 35-49. Bangi: Kuala Lumpur.

NorAsyikin Osman (2017). Student Readiness in Learning Arabic Languages Based on Blended Learning. International Journal of Applied Linguistics and English Literature, 6(5).

Oliver, M., \& Trigwell, K. (2000). “Can 'Blended Learning' Be Redeemed?”. E-learning and Digital Media, 2(1):17-26.

Syed Lamsah Syed Chear (2017). Pengajaran dan Pembelajaran Melalui Aplikasi Whatsapp dan Telegram di Universiti Swasta. Jurnal Pendidikan Malaysia, 42(2):2017.

Talib N. (2016). Mengkaji Pentaksiran Pengaturcaraan Komputer Bedasarkan Penyelesaian Masalah Kreatif Menggunakan Pendekatan "Grounded Theory". Journal of Advance Research in Social and Behaviour Sciences.5(1): 25-38.

Thomas K.F. Chiu \& Daniel, C. (2015). Design of Learning Objects for Concept Learning: Effects of Multimedia Learning Principles and an Instructional Approach. Interactive Learning Environments.

Vidya (2016). Pengertian, Karakteristik dan Manfaat E-Learning.

Yusof, S.S. M., (2017). Keberkesanan Penggunaan Alat Bantu Mengajar Interaktif bagi Meningkatkan Kefahaman Konsep Pengaturcaraan dalam Kalangan Pelajar. 